\title{
GASTRO NEWS
}

The World Congress of Gastroenterology was held October 2 to 7, 1994 in Los Angeles, California. Approximately 10,000 medical scientists from around the globe were in attendance.

Digestive diseases rank among the leading causes of death by illness in North America. Worldwide, diarrheal diseases such as cholera and dysentery are the third leading cause of death by illness, killing 3.5 million children annually. Digestive diseases cost the western world more in health care costs, lost work days and premature death than any other disease category, at a level similar to heart disease. It was to address these statistics that a distinguished faculty of 750 prominent specialists from more than 50 countries led the Congresses.

In addition to approximately 3300 posters and 250 oral presentations, there was several unique, innovative programs, such as the Young Clinicians Program, for which the Congress provided scholarships for more than 300 young physicians to take part in all aspects of the week's activities.

Topics explored over the week included biology of colon cancer, new endoscopic techniques, surgical treatment of colorectal disease, liver and intestinal transplantation, gene therapy, nutrition management, alcoholic liver disease, Helicobacter pylori, hepatitis B and C, enteric infections and novel pharmacological approaches to gastrointestinal disease. 


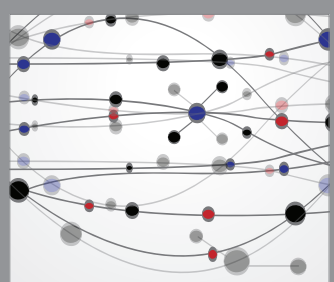

The Scientific World Journal
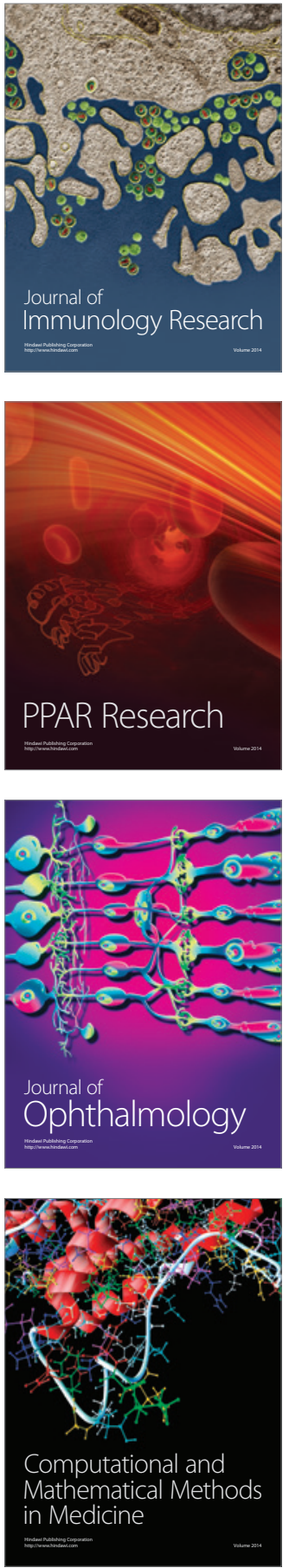

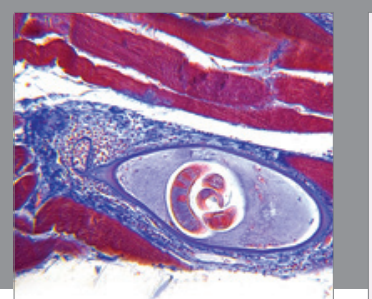

Gastroenterology Research and Practice

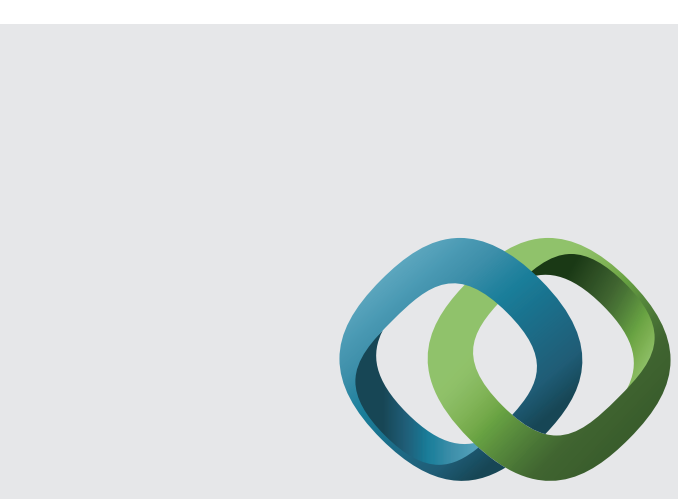

\section{Hindawi}

Submit your manuscripts at

http://www.hindawi.com
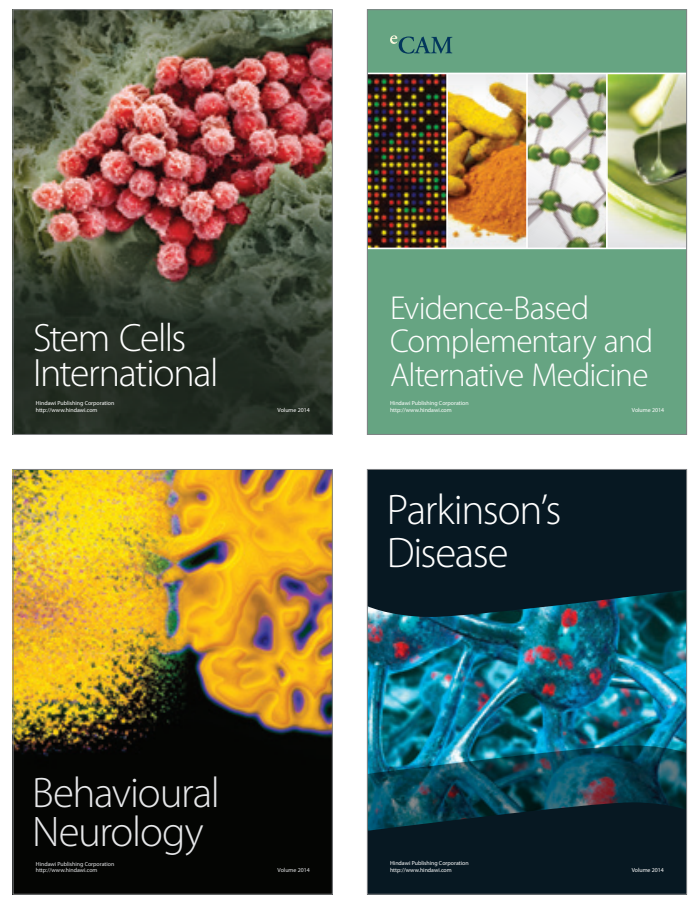
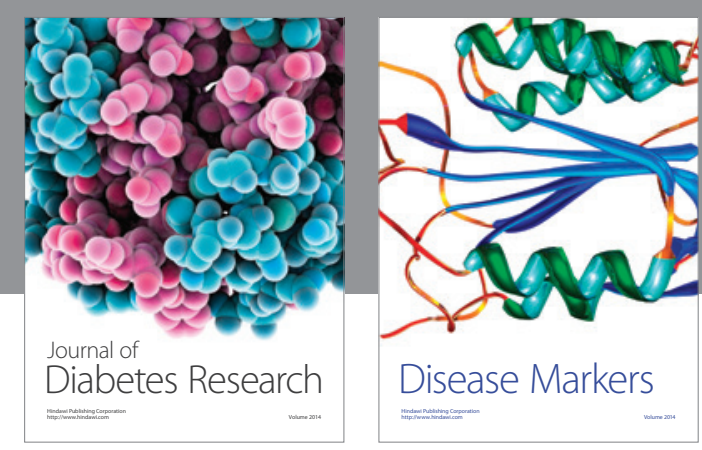

Disease Markers
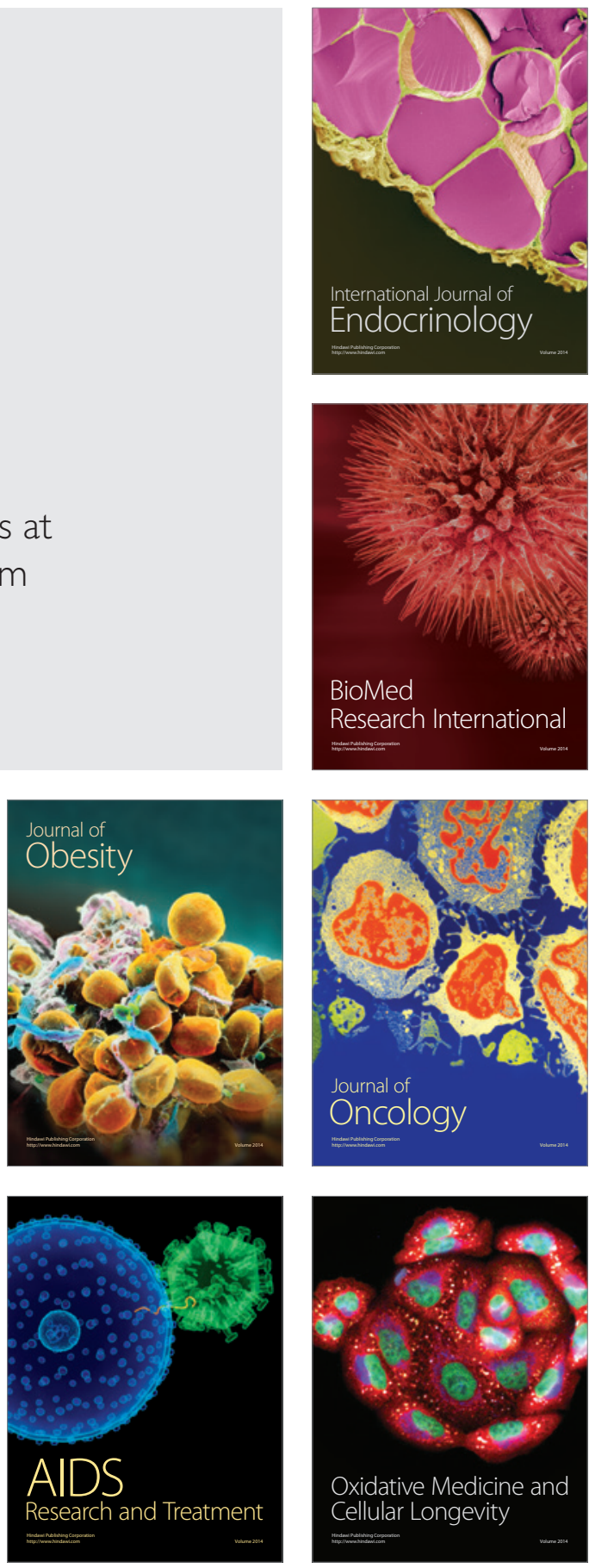